\title{
A Smart Approach for E-Learning Domain: The Use of Business Models and Semantic Technologies
}

\author{
Georgiana STĂNESCU (NICOLAIE) \\ The Bucharest University of Economic Studies, Romania \\ georgianastanescu17@gmail.com
}

By making a topology of the benefits and disadvantages in e-business, we can see why a business presence in the web environment is better than a traditional one and mentioned the companies that have already begun to introduce technology into their platforms. Analyzing the major semantic technologies and the current state of their use in e-business, I will be able to demonstrate the viability of an e-business model and to discover the areas for which it is opportune to implement a technology. In this article, I will present the ways to use software products and I will mention the most usable and important, which facilitates the integration of business in the web domain.

Keywords: E-business, Semantic web, Semantic technology, Business models, Web

$\mathbf{1}^{1}$ Introduction

Over time, the demands of society have led to technological developments, which have helped create a more accessible and usable web environment. It is already a fact that we live in a digital era where society needs a more usable and accessible web environment. Looking back, we can see that the emergence of the World Wide Web in 1989 had a constructive effect on society. English programmer Tim Berners-Lee, who proposed the World Wide Web [1], aimed to automate and facilitate the exchange of information between people. Tim Berners-Lee debated 'the problems of loss of information about complex evolving systems and derives a solution based on a distributed hypertext system' [1].

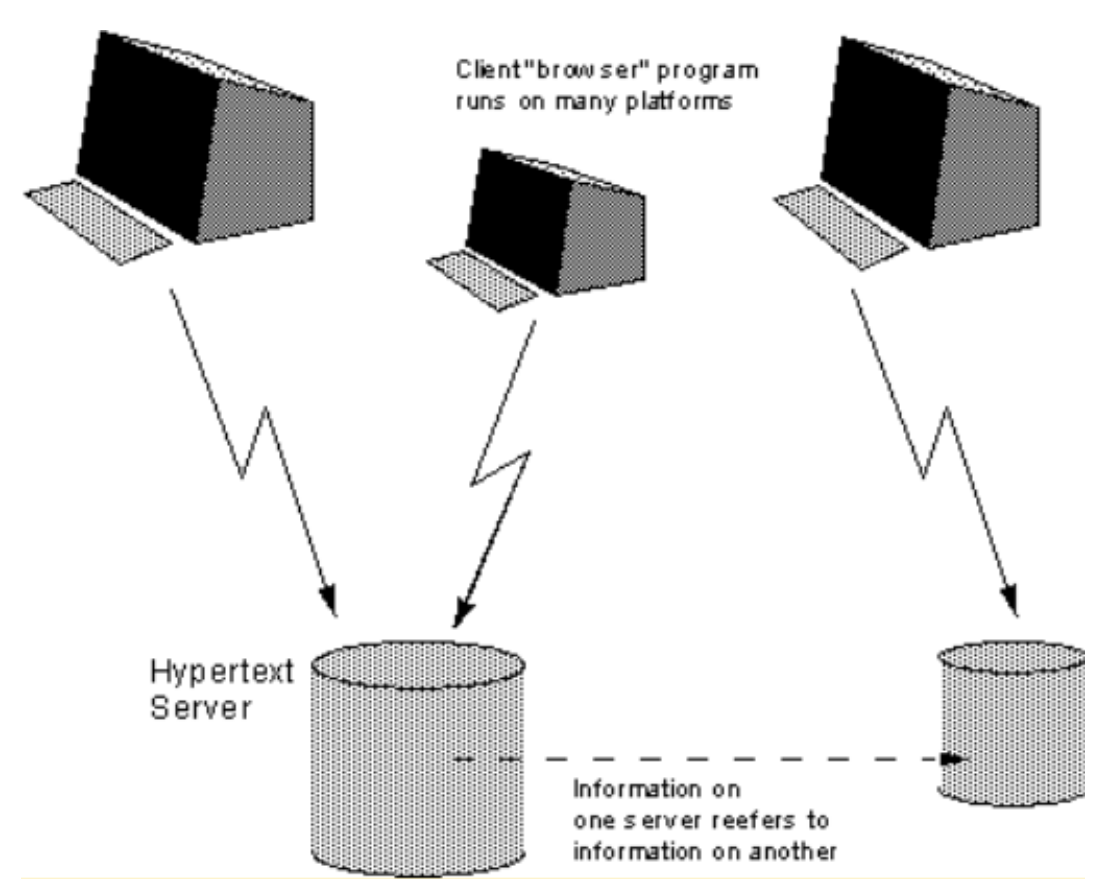

Fig. 1. 'A client/server model for a distributed hypertext system' [1]

With the use of this hypertext system, numer- ous facilities, activities, which were considered traditional, were now available on the 
web environment. But over time, the data available online has increased and the web domain needed a more reliable technology. This need has been fulfilled with the introduction of semantic technologies, which will make the web domain much more efficient.

In the year 2001, the term of semantic web was first mentioned in an article [2] by Tim Berners-Lee, James Hendler, and Lassila. With the emergence of semantic technologies, there has been a simplification of the relationship between existing software products. The World Wide Web is designed to be easily adaptable and usable in any field. Tim Berners-Lee argued that the semantic web 'will bring structure to the meaningful content of Web pages, creating an environment where software agents roaming from page to page can readily carry out sophisticated tasks for users.' [2]

The importance of this article is amplified by the use of semantic technologies in e-business. Thanks to semantic technologies, we can see that the e-business field takes full advantage of all the privileges offered by the web. Once a business is online, it is much easier to promote its interests and brings a wealth of benefits to the company.

The e-business domain is of great interest and with an impressive development in the last period. The basic idea in e-business is to translate a physical business into an internet accessible one.

The term e-business was introduced by Lou Gerstner (Corporate Executive Officer at IBM) in 1997, offering a new vision of the business. We can even say that e-business refers to the development of the traditional business domain with the help of the internet, and then to completely transform the business model of the companies.

The e-business domain has an impressive development in the last period. The basic idea in e-business is to translate a physical business into an accessible internet one. Living in a very competitive economic environment, ebusiness can be seen as a new form of communication between the seller and the buyer, and in order to facilitate this exchange of in- formation, e-business models are implemented.

\section{The e-business concept in a company}

We can say that the idea of an e-business came to life when traders realized they could use the web to promote and sell their products, in order to make a bigger profit and attract new customers.

Initially, e-business was known as e-commerce, because selling and promoting products was done via the internet. Over time, the e-business concept was introduced that provided complete services both for the business and for their clients.

In the early 1950s, business models were used by McDonald's and Toyota Motor Corporation. In the 1960s, hypermarkets, for example, Walmart, began to adopt business model strategies. The 1980s were marked by the emergence of computers, Intel and Dell Computer, which forced a new development of business strategy, and that in the 1990s the online trade would be further developed through the emergence of eBay and Amazon.

In the article 'Introduction to Internet Business' [4], Daniel Amor recalls the definition of the term e-business provided long ago by IBM: 'a secure, flexible and integrated approach to delivering differentiated business value by combining the systems and processes that run core business operations with the simplicity and reach made possible by Internet technology.' [4]

At the theoretical level, we can state that ebusiness depends on the interconnection of information in the web domain. When we think of the term e-business, we refer to how a company is running, using and applying technological means in the business process. Nowadays, the most difficult part an e-business faces is to provide the necessary reliable solutions in a business environment.

Of all the challenges which e-business is facing today, we can mention the following:

- the available data are variable and growing;

- new product models are available and this results in increased data usage;

- fragmented data, hard to find. 
E-business refers in principle to 'transforming key business processes by using Internet technologies.' [5]

Numerous studies on technology development and web-based innovation encourage the transformation of a business into an e-business. Since 1996, Clayton M. Christensen and Joseph L. Bower have written about Clayton M. Christensen and Joseph L. Bower in the article 'Customer Power, Strategic Investments and the Failure of Top Companies' [6], showing the positive effects of web-based clients, advising companies to invest more much in today's technology: 'when significant customers ask for it, enough impetus can develop so that large firms start and successfully carry out innovations, even those technologically challenging or those that require very different skills than they initially possessed.' [6]

E-business can be seen as a new form of communication between the seller and the buyer. A relevant e-business study would be 'An Analysis of Adopting an e-Business and Its Impact on Business Performance' [7], which highlights the reasons why companies adopt the e-business model in order to manage the processes more efficiently domestic affairs. The article highlights the benefits of an ebusiness business such as increasing business performance and efficiency, sales growth, and customer satisfaction. It demonstrates how the transition to e-business has a remarkable influence on business development.

The advantages and disadvantages of an ebusiness can both be faced by a company, but the client can also be affected by a business that is not well structured.

An important advantage for any business would be the internet. With the help of this and by accessing the digital data stream, companies can promote their business and convince customers to buy.

Analyzing the current market, it can be noticed that organizations using the internet to implement business operations get remarkable advantages and numerous opportunities for profit growth, compared to potential competitors who do not adopt new technologies to promote information and communication with customers.
Looking at a company's perspective, we can mention the following notable advantages that semantic technologies offer to an e-business:

- the internet is accessible from anywhere, anytime and by anyone;

- web services have also expanded on mobile devices, tablets and customers have the necessary information anytime;

- a greater geographic expansion, as the location is not a problem if the customer can access the company's information from anywhere.

- $\quad$ promoting the company using the web domain, so it aims to improve the profit by creating new opportunities and finding new clients;

- hierarchizing clients and improving their relationship with them, having the opportunity to loyalty to certain clients and to offer promotional products;

- lower management costs, a promotion site requiring minimal investment from a traditional store, many products can be made available to customers at a lower price, so they are also attracting low-cost customers.

The e-business domain has not only benefited companies, it also considers the needs of the clients and offers many advantages, such as:

- easy access to information, a quick search for services and products at anytime and anywhere;

- reduced time, the client can choose what he wants without losing time through the store and without consulting an employee;

- a wide range of products and services, the ability to compare and choose what's best for the buyer.

According to Daniel Amor [4], the 'companies who want to invest in electronic business are not restricted to the publishing, entertainment, information, and software industries, as one could imagine. Every company will need to invest, as electronic business is more than just selling things online, it means moving processes and communication online, and this affects every company.' [4]

\section{E-business models: benefits, strategies and computer systems}


In an attempt to define the concept of business model, we can observe that it is a term composed of the following two definitions [8]:

- Business: Purchasing and selling goods and services or a company that does this to earn money.

- Model: A representation of an element, whether a physical object that is usually smaller than the actual object, whether a simple description of the object that could be used in the calculations.

Combining the two definitions, it results in a process whereby a company sells or offers services, and this activity gains profit. The goal of creating a business model is to understand and describe how a company works.

Over time, since the year 1975 when the term of the business model was first mentioned, there have been various interpretations and definitions of it. In the article ,Business Models for Electronic markets' [9] written by Paul
Timmer in 1998, the business model was defined as 'an architecture for the product, services, and information flow, including the description of various business actors and their roles.' [9] He argued that the business model should have in the component and a marketing model: 'A business model itself does not yet offer an understanding of how it will contribute to achieving the business mission of any company. We need to know the company's marketing strategy to assess commercial viability and answer questions such as: How to build the competitive advantage, what is positioning, what is the marketing mix and what is the market strategy Products. It is, therefore, useful to identify beyond business models and marketing models.' [9]

The authors Mutaz of Debei and David Avison, in the work 'Developing a unified framework of the business model concept' [10], make a parallel between the traditional and digital business:

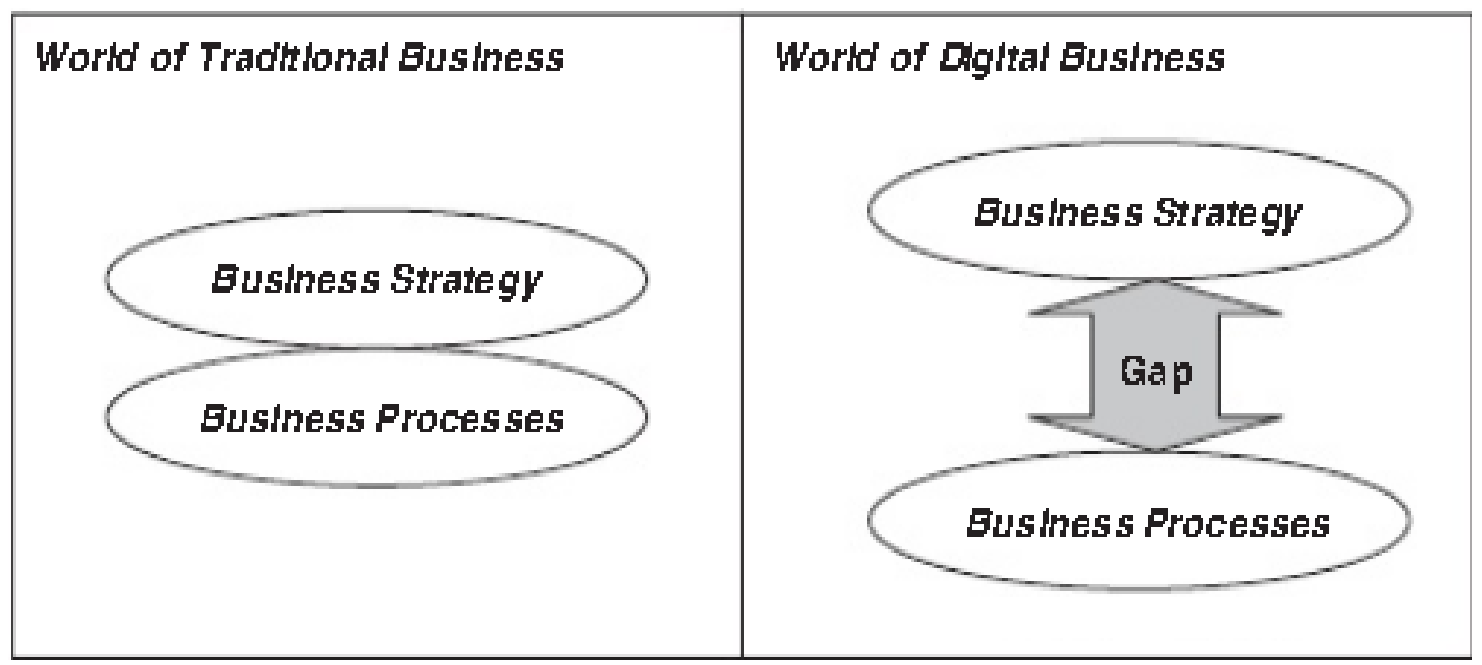

Fig. 2. Comparison between the traditional and modern digital world [10]

The traditional business is part of a stable environment with a well-known market and a minimum level of competition, with minimal knowledge of the business process. This is based on a simple, static and limited process in terms of expanding the business.

About the digital business, this is part of a dynamic environment, and the business is sometimes expanded at a national level and has a high level of competition. The business process here is geared towards adopting technology and expanding ways to do business.

Understanding the business model is determined by its place in the company. To cover that gap from figure number 2 , the business model in a company works as a bridge between the strategy and the business process. Considering information and communications technology, the modern business world re- 
quires the presence of a business model as efficiently as possible to cope with the inevitable changes in technology.

As far as you can see in the next figure, the business model must consider many factors and find the optimum solution to adapt to all requirements and obtain an optimal business strategy for the company.
The business model of a company must cope with the very dynamic market, changes in the legal or social environment, the ever-changing technology, competition and customer requirements, as far as can be seen in the following figure:

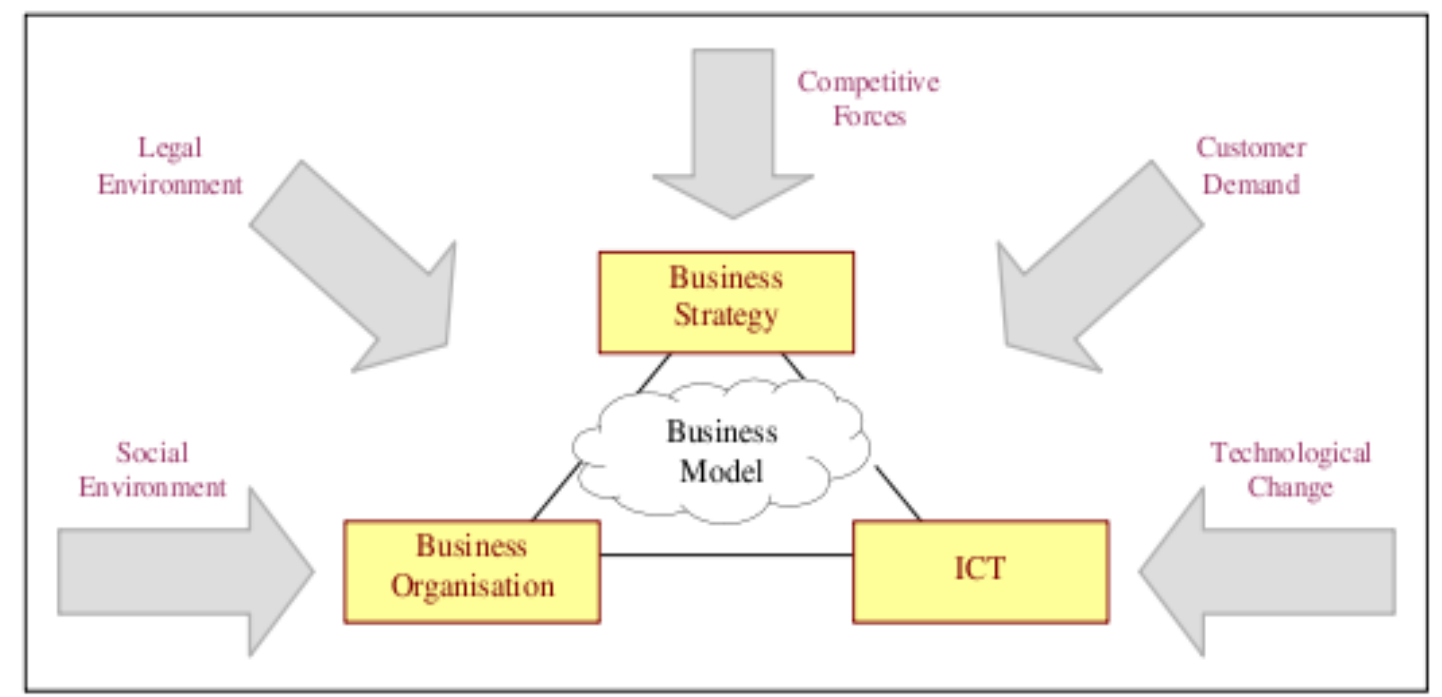

Fig. 3. Environment, business models, strategies, processes and information systems [8]

The surrounding factors put pressure on an organization through the presence of diversified workforce, the technology that brings a very large and hard to process information, customers with varied consumer requirements, location and level competition very strong global.

In this business environment, a company must cope with pressures and come up with an innovative response to generate profit. Here come the business models, creating a homogeneous link between all the requirements of society, processes, strategies and information systems.

According to the article, The role of the business model in capturing the value of innovation' [11], a business model is 'a description of how the company intends to create value on the market. This includes the unique combination of products, services, image and distribution that the company transmits. It also includes the basic organization of people and operational infrastructure they use to achieve their work.' [11]

After 2000, the concept of business model has received tremendous attention, 'it is helpful for companies to use e-business tactics when clearly defining e-business models. Additionally, such rigorously-defined models can assist firms to assess, alter, and even stimulate the business.' [12]

As the business environment is becoming more and more dynamic, in order to reduce the risk of a business, it is necessary to consider developing and implementing an ebusiness model.

In the below figure we can see a business logic triangle, which demonstrates that a business model is created in terms of strategies, relationships, processes, practically is an architectural representation of the implementation of a business idea. 


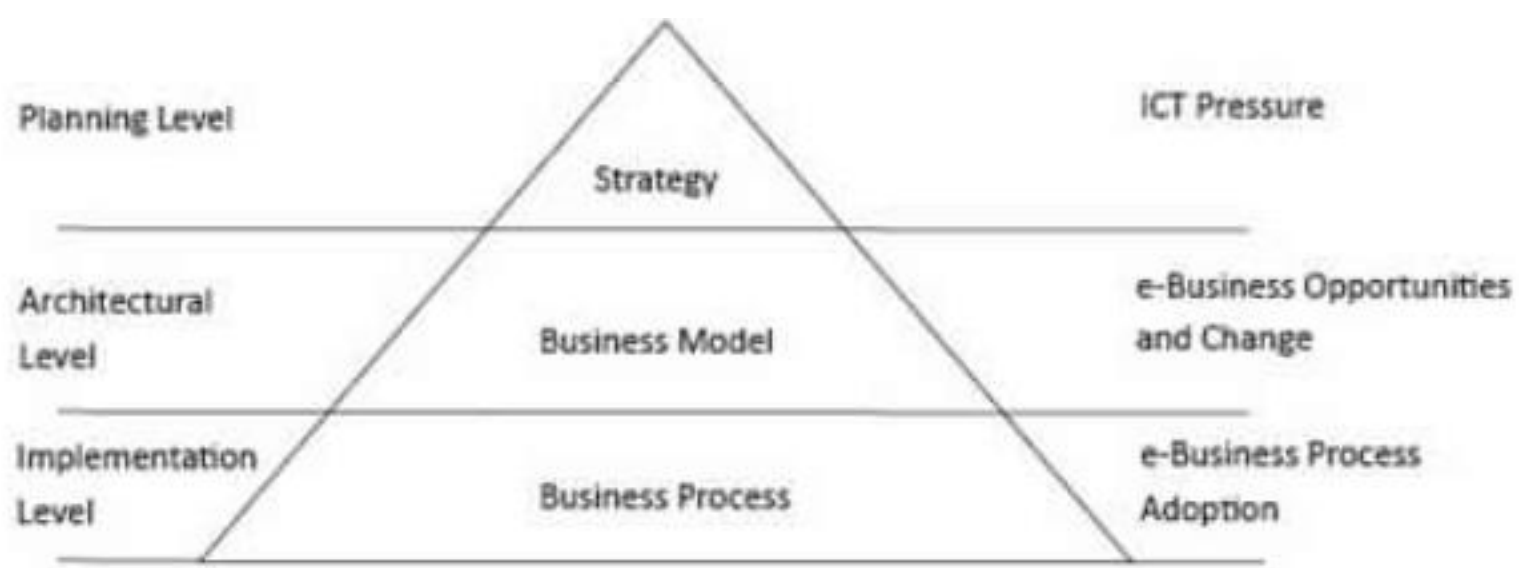

Fig. 4. Triangle of business logic (Osterwalder and Pigneur, 2002) [12]

The triangle of business logic demonstrates that a business model is created taking into account strategies, relationships, processes, it is basically an architectural representation of the implementation of a business idea. ,

A more recent definition of the business model is the one from Michael Rappa (2010): , The business model spells-out how a company makes money by specifying where it is positioned in the value chain. Some models are quite simple. A company produces a good or service and sells it to customers. If all goes well, the revenues from sales exceed the cost of operation and the company realizes a profit.' [13] A business model defines the organization of both products and services, information flows, as well as the source of benefits for suppliers and customers.

To be as viable as possible, a business model must consider the following aspects:

- a promotional strategy;

- to bring news to the existing business market;

- to identify what kind of category of customers it wants to attract;

- to produce profit through the services or products offered to customers;

- competitive advantages;

- to identify the pitfalls and risks of a business.

Business models can also provide the following functions, according to [14]:

- identify a market segment, i.e. users to whom technology is useful and for what purpose;
- define the structure of the value chain in the company, this is necessary to create and distribute the offer;

- estimation of the structure of costs and profits, taking into account the value proposal and the structure of the chosen value chain;

- describe the company's position within the network of values linking suppliers and customers, including identifying potential competitors;

- formulating the competitive strategy, whereby the innovative company will win and have the advantage over its rivals.

Today we have the opportunity to create the desired business model via a design tool available online and often free and handy to anyone.

Regardless of the chosen business model, they all have an architecture and a specific purpose. To be easier in understanding and applying these business models, we can call on various web tools for visual modelling of the business, such as:

- https://canvanizer.com/

- https://strategyzer.com/

- https://bmfiddle.com/

- http://www.plancruncher.com/

- http://www.boardofinnovation.com/business-model-templates-tools/

The application of any tool in the listed helps to achieve a vision of the evolution of a business and its structure. 


\section{Semantic technologies applied in busi- ness models}

The role of semantic technologies in business models can be best understood by 'exploring the relations between semantics, syntax, and notation of modelling languages'. [15] Online users rely on available offers found at a simple internet search for the products or services they want. Semantic technologies provide users with a search process based on the attributes of the product or service, which best correspond to their needs, providing relevant information in due time. The sale of online products is much more efficient with the implementation of semantic technologies.

Semantic technology provides intelligent data integration and more agile access to different types of data by means of specific languages. A business model is constantly changing due to the dynamic environment of the business market. When the market changes, the business model must adapt to maintain the viability of the company and of course the level of profit.
According to [16], 'an indispensable factor for a successful business model is the power of his transformation or variability. A rapid adjustment to the new market is warranty initial success, as well as a great advantage over the competition. Especially if it comes to the first mover of the new patented technologies that easily win customers and guarantee the rapid development of the organization. It is essential to change existing business models in relation to the new situation as the market and the environment.'

Using semantic technologies in existing business models, customers can quickly access the information needed for products or services, purchase products, pay online, etc.

Integrating semantic technologies into the chosen business model, companies can have a different view of the products or services offered. But for this, we need to know how semantic technologies are working and we need to understand it's architecture. From the following figure we can see the basic schema of a semantic web architecture and the components which are used:

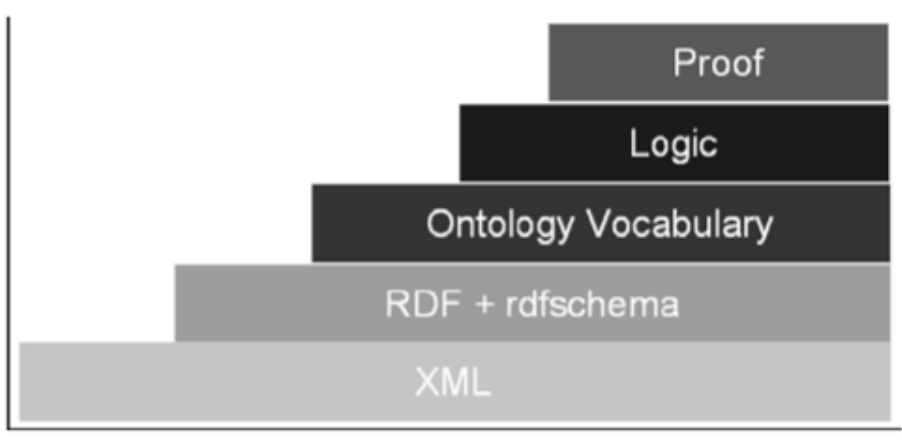

Fig. 5. 'Layers of the semantic web architecture' [17]

At the syntactically level, the XML language is used, because it is similar to HTML and allows the structuring of the Web content, and accessibility to information is easier, due to the data storage method. The XML language is very widespread in the web domain and is often used for data transfer.

As for the basics, an XML document contains the following:

- bookmarks or tags, starting <tag > or end $</$ tag $>$, each containing the characters ' $<$ ' and ' $>$ ' and are used to delimit the areas containing information in the document, as follows:

<tag> section <tag>

- the XML version used to browse the document is currently 1.0 :

$<$ ? $x m l$ version $=" 1.0 "$ ? >

- the document type declaration is optional and refers to the encoding of the characters used:

$<$ ? $x m l$ version $=" 1.0 "$ encoding $=$ "UTE-8 "? >

- table attributes (<table $>)$, menu $(<\mathrm{menu}\rangle)$, document $(<\mathrm{doc}\rangle)$, images $(<$ img $>$ ). 
The syntax of an XML document is divided into three logical structures as follows:

- the prologue (contains the declaration of the document and version);

- the definition of the document type (contains classes and rules);

- the root element (comprises the body of the document, Processing instructions, attributes, etc.).

The simplest example of using XML language is the following:

<?xml version="1.0" encoding="UTF-8"?>

$->$ Prolog

<!DOCTYPE MAIL SYSTEM "mail.DTD">

-> Document type definition $<$ mail>

-> Root element

$<$ TO>georgianasta-

nescu17@gmail. com $</$ TO $>$

$<$ FROM>nastaseflase. ro</FROM> <SUBJECT>Report</SUBJECT> <BODY>

Don't forget the annual re-

port!

$</$ BODY $>$

$</$ mail $>$

Considering that it is a simple language to use and integrate, we can find a wide variant of editing tools. The most used is Notepad ++ , can be installed on any computer and does not require purchase. With more complex use are Eclipse (https://eclipse.org/), Oxygen XML (http://www.oxygenxml.com/), Liquid XML Studio (https://www.liquid-technolo- gies.com/), Beyond XML (http://www.beyondxmlsolutions.com/),

Editix

(http://www.editix.com/), Altova (http://www.altova.com/xml-editor/) and StylusStudio (http://www.stylusstudio.com/)

If we want to ease our work even more, in creating an XML document we can use stencils, for example, http://www.xmlpatterns.com/, which offers solutions for integrating data in the desired form.

If since a couple of years ago we had just distributed data on the internet, now, with the help of ontologies, data are connected to each other, giving users better visibility of the semantic web.

OWL (Web Ontology Language) language is an ontological language, composed of classes and properties between them. This is a vital component for the semantic web because it is like an extension of the XML documents and RDF.

At syntactically level, each ontology begins with a header, which contains a title, after which the details of the ontology are followed: <owl:Ontology rdf:about=" ">

.... Details...

$<$ lowl: Ontology>

The main role of an ontology is to classify things that have the same semantic meaning. OWL language achieves this by using classes and subclasses. All elements of a class share the same set of features, as evidenced by the following example:

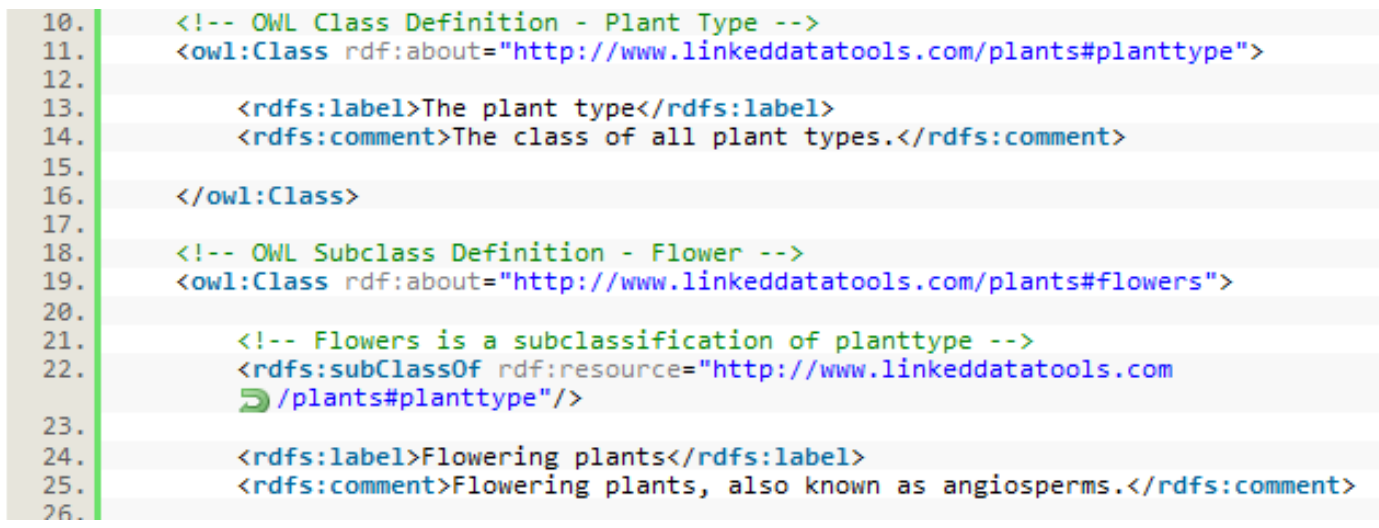

Fig. 6. OWL language [18]

The most widespread and used ontological tool is the Protégé editor (http://protege.stanford.edu/), developed by Stanford Research
Centre for Biomedical Informatics. It was specially designed for the development and support of ontologies, enabling scientists to use ontologies. 
Among the ontological publishers can also mention the following: $\mathrm{NeOn}$ Toolkit (http://neontoolkit.org/wiki/Main_Page.html), OWL GrEd (http://owlgred.lumii.lv/), Cognitum Fluent Editor (http://www.cognitum.eu/semantics/FluentEditor/), etc.

The next step of a semantic web architecture presented in figure number 5 is the logical language. These help to distribute ontologies between various web applications and refer to the OIL (Ontology Inference Layer) and RDFS (Resource Description Framework) languages.

An example of the use of logic languages would be their integration into a website for ecommerce, promotion, and sale of products, where the customer can choose the desired product after a classification ' on the basis of a specific ontologies, this aspect Facilitating the "intelligence" search of a product on various criteria or taking into consideration the user's preferences, based on the shopping categories already made. ' [4]

According to [16] with the help of semantic technologies, the business model has the following benefits:

- easy to use;

- low costs;

- sure;

- maximizes the value of the information;

- provides flexibility in exchanging information;

- effective.

Another major advantage of using semantic technologies is the application of business models and other areas such as medicine, elearning, agriculture, other companies or business areas that are not yet sufficiently developed. Also, semantic technologies improve the economy and reduce risks at all stages of the solution lifecycle: research and development, deployment and operation, maintenance and evolution'. [16]

There is a possibility as occasional different parts of the business process to require an update to use existing new technologies. Using semantic technologies can automatically check if there is any news or if new updates are supported by the system and if the 'interaction between different companies or even departments of one company is hindered due to the used terms, standards, etc. Annotating the process models with semantic information (using a domain ontology which captures the domain of interest and a modeling language ontology that includes a description of the concepts in the process model) offers the possibility to interact across company or department borders.' [19]

\section{E-learning business perspective}

To summarize everything and to prove that both business models and semantic technologies have huge potential if they are used together, I chose the Canvas model and applied it to the field of e-learning.

According to an article written by Michael Rappa [13], business models are implemented in different ways, depending on the nature of the business.

E-Learning is a successful combination of the traditional model of teaching, with the existing technology and first appeared in early 1990, that responded to the educational needs of the people.

According to article 'New semantic technology trends an opportunity for e-learning environment' [20], the e-learning has grown significantly 'based on the evolution of semantic technologies, is being used by a lot of teachers that want to share their knowledge to students and is very popular with companies, which are looking forward in offering a learning program to employees. The e-learning domain combined with semantic technologies has a huge potential and is a successful combination of the teaching system.' [20]

Semantic technology provides the opportunity to understand human requirements using semantic structures. The evolution of web technologies and semantic technologies highlights the advantages of using them in e-learning. 


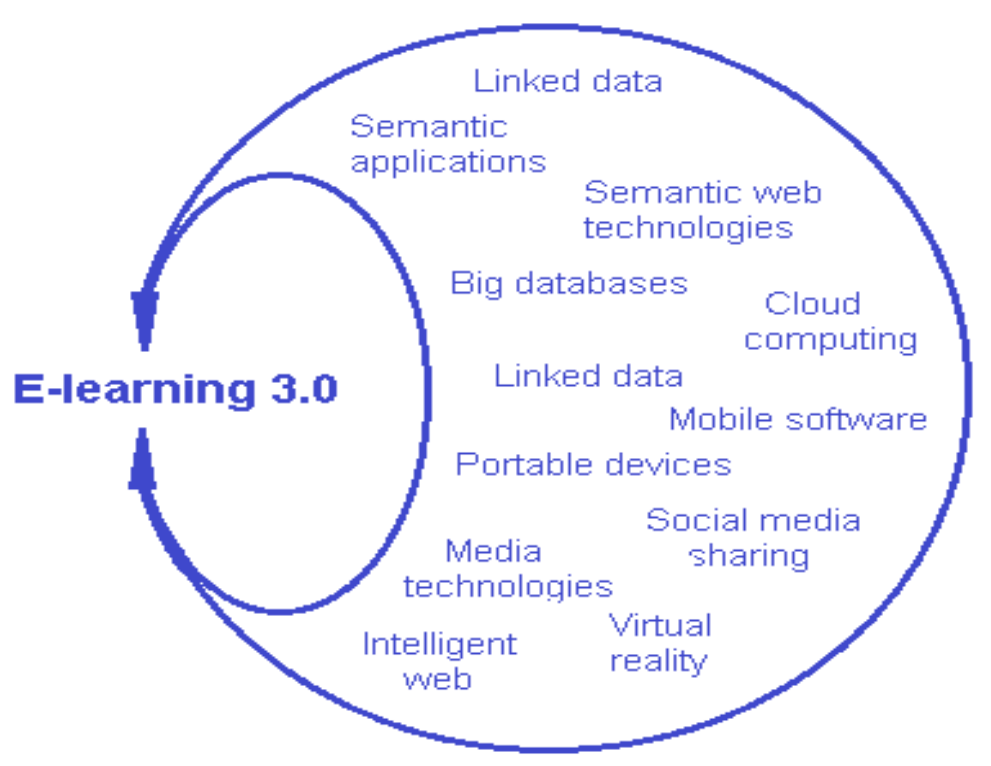

Fig. 7. E-learning factors [21]

In the above figure, it can be seen that the elearning is based on new technology, including semantic technologies, semantic web, cloud computing, etc. E-learning is like 'a combination of a lot of factors and is making use of all the new technology that web 3.0 has to offer. In this way, the learning process is much flexible, accessible and we can easily sort what we want to learn, choose how we want to learn and where we want to access the learning process.' [21]

As e-learning is an area that uses semantic technologies intensively and all the e-business potential, I have chosen it for the application of the Canvas business model.

The Canvas model was first proposed by Alexander Osterwalder and Yves Pigneur in the year 2010 and is considering distributing the important components of a business on a canvas divided into nine quadrants.
According to [22], the Canvas business model is 'popular with entrepreneurs and intrapreneurs for business model innovation' and is offering the following:

- focuses on what the business offers and improves the business plan [22];

- flexible, it is much easier to look at the business in a prospect of planning and optimizing something that is on one page [22];

- transparency, the model is easy to understand, having all the information gathered in one place [22].

Using the free Canvas model [23] template available online, the following scheme can be generated, in which I have completed the nine blocks with the necessary information in the field of e-learning: 


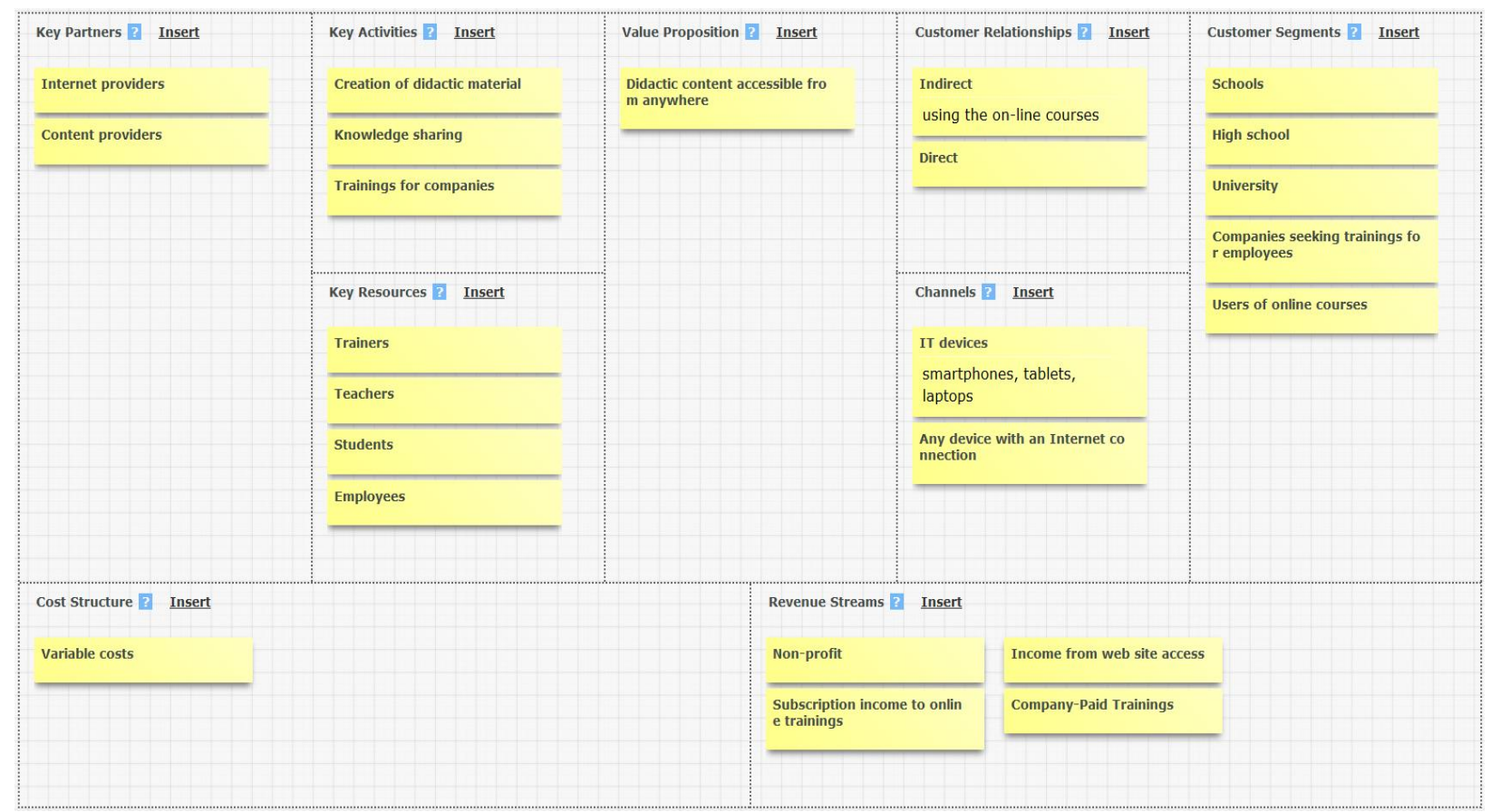

Fig. 8. Example of pattern Canvas model applied in e-learning [23]

In this model, I tried to capture the possibilities offered by the e-learning environment and the changes generated by it. The current Web is one of the key partners because it is in collaboration with the needs of society. As long as we have a viable internet connection, we can achieve the values proposed by this model, which is to access the data needed for the learning process from anywhere, even from home, not only to the office or school. Key resources remain the same as in the traditional way of learning because trainers and teachers are the ones that create content and make it available to students.

Analysing all nine components, we realize that they play an important role in defining the business model for e-learning, unable to exist without each other. In the chosen model, all necessary information communicates with each other through channels.

In order to distribute the didactic material, we must consider some key activities, one of which is knowledge sharing. The most suitable technology for this activity is semantic technology, revolutionizing the e-learning mode by using the languages described above. This model suggestion is represented in the virtual environment with the help of visual and textual information, relying heavily on the content provided. With the help of semantic technologies, this example takes advantage of the web's advantages, being much easier to use.

An advantage of using semantic technologies in this model is simplifying the search mode. A student always going to look for keywords, not after complex phrases, therefore the reasoning between the terms defined helps a more effective search.

\section{Conclusions}

Over the years, business models have become more sophisticated. Today, the type of business model used by a company could depend on how technology is used and it can make a difference between a profitable business and one which is not.

I choose to apply a viable business model in e-learning, because with the use of current technology, the e-learning process can reach many users, with minimal efforts and costs.

E-learning is, in fact, a business because we can find companies which offer learning methods to their clients, corporate training for employees or paid learning platforms which can be accessed globally.

In addition, it can also be taking into consideration the outsourcing and globalization of a learning provider company, which is achieved much easier with a good business model. The 
use of a business model in a company which provides learning courses or training can be an innovation, continuously improving the business, to cope with global competitiveness. If we were to answer the question 'Why is it necessary to use a business model?', according to [12], we can say that applying a business model to a company would come up with the following advantages:

- an e-business model could assist in identifying and realising the relevant elements in a particular area and the connections between those elements [12];

- managers could easily communicate their understanding of an e-business with other stakeholders through the assistance of formalized models [12];

- it is easier for business model planners to modify relevant elements from the existing models [12].

The e-learning domain is making use of a lot of learning data available on the web environment, so it needs a proper e-business model.

The e-learning process has evolved from the one focused only on distributing content to a more interactive one. With the evolution of semantic technologies, the beginning of the 3.0 Web era and a proper business model, the elearning environment began to be accessible without too much effort from the learners and to focus on the needs of society.

In this article, I have highlighted that the potential of semantic technologies, applied in the business model created for the e-learning field, helps to provide quality education, which can be quickly spread all over the technological devices.

\section{References}

[1] Semantic web, Available: http://semanticweb.org/wiki/Main_Page.html

[2] Cody Benson (2007), Introduction to the Semantic Web Vision and Technologies, Available: http://www.semanticfocus.com/blog/entry/title/introduction-tothe-semantic-web-vision-and-technologies-part-1-overview/

[3] John Davies, Rudi Studer, Paul Warren (2006), Semantic Web Technologies: Trends and Research in Ontology-based
Systems, Publishing John Wiley \& Sons, England

[4] Sabin-Corneliu Buraga, Considerations Regarding the Use of Semantic Web Technologies in the Context of E-business Applications, Economic Informatics Magazine, Bucharest, nr. 3(35)/2005

[5] Want a semantic web/ linked data job? Available: http://afterglowlee.blogspot.co.uk/2011/07/want-semantic-web-

linked-data-job.html

[6] Clayton M. Christensen, Joseph L. Bower, Customer Power, Strategic Investment and the Failure of Leading Firms, March 1996, Available: http://www.jstor.org/stable/2486845

[7] Fang Wu, Vijay Mahajan, Sridhar Balasubramanian, An Analysis of E-Business Adoption and its Impact on Business Performance, April 2003

[8] Alex Osterwalder, The Business Model Ontology a proposition in a design science approach, 2004, Available: http://www.hec.unil.ch/aosterwa/PhD/Osterwalder_PhD_BM_Ontology.pdf

[9] Paul Timmers, Business Models for Electronic Markets, April 1998, Available: http://www.cs.uu.nl/docs/vakken/ec/Timmers_BMem.pdf

[10] Al-Debei M. Mutaz si Avison David, Developing a unified framework of the business model concept, European Journal of Information Systems, Vol. 19/2010

[11] Henry Chesbrough, Richard S. Rosenbloom, The Role of the Business Model in Capturing Value from Innovation: Evidence from Xerox Corporation's Technology Spinoff Companies, Available: https://pdfs.semanticscholar.org/2804/af7e7a7ddffffbc49de 9869bbc496f7b8f11.pdf

[12] Damien Wyatt (2007), The impact of online word of mouth on consumer behaviour in the cosmetics industry, Available: http://www.ivoryresearch.com/writers/damien-wyatt-ivory-research-writer/

[13] Michael Rappa, Business Models on the Web, 17 January 2010, Available: http://digitalenterprise.org/models/models.html 
[14] Henry Chesbrough, Richard S. Rosenbloom, The Role of the Business Model in Capturing Value from Innovation: Evidence from Xerox Corporation's Technology Spinoff Companies, Available:https://pdfs.semanticscholar.org/2804/af7e7a7ddffffbc49de 9869bbc496f7b8f11.pdf

[15] Michael Fellmann, Patrick Delfmann, Agnes Koschmider, Ralf Laue, Henrik Leopold, Andreas Schoknech, Semantic Technology in Business Process Modeling and Analysis.Part 1: Matching, Modeling Support,Correctness and Compliance, Available:http://www.henrikleopold.com/wp-content/uploads/2015/01/2015_EMISA_SemanticTechnology_Part1.pdf

[16] Borce Cifliganec, Dimitar Trajanov, Semantic web business models, 2011, Available: http://ciit.finki.ukim.mk/data/papers/8CiiT/8CiiT-36.pdf

[17] Khurram Naim Shamsi, Zafar Iqbal Khan, Development of an e-learning system incorporating semantic web, Available: https://arxiv.org/ftp/arxiv/papers/1209/1209.3117.pdf
[18] Introducing RDFS\&OWL, Available: http://www.linkeddatatools.com/introducing-rdfs-owl

[19] Florian Lautenbacher, Bernhard Bauer, Christian Seitz, Semantic Business Process Modeling - Benefits and Capability, Available: erx.ist.psu.edu/viewdoc/download?doi=10.1.1.520.4568\&rep=rep1\&ty pe $=$ pdf

[20] Georgiana Stanescu, New semantic technology trends an opportunity for e-learning environment, The 14th International Scientific Conference eLearning and Software for Education Bucharest, April 1920, 2018

[21] Georgiana Stanescu, The evolution of elearning based on web3.0 and semantic technologies, The 12th International Scientific Conference eLearning and Software for Education Bucharest, April 2122, 2016

[22] Alexander Cowan, The 20 Minute Business Plan: Business Model Canvas Made Easy, Available: http://www.alexandercowan.com/business-model-canvas-templates/

[23] Canvanizer, Available: https://canvanizer.com/new/business-model-canvas

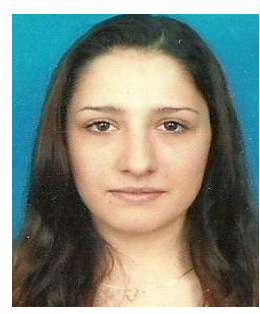

Georgiana STĂNESCU (NICOLAIE) graduated from the Faculty of Cybernetics, Statistics and Economic Informatics of the Bucharest University of Economic Studies (ASE) in 2010. After that, she obtains a Master Degree in Multimedia and Audiovisual Production from Faculty of Journalism and Mass Communication, in the Master of multimedia and audiovisual production, Bucharest (Romania). In present, she is a Ph.D. student in Economic Informatics at Economic Informatics Doctoral School, Bucharest University of Economic Studies (ASE), specialization: semantic technologies applied in e-business. 